\title{
THE INFLUENCE OF SOIL MOISTURE TRANSFER ON BUILDING HEAT LOSS VIA THE GROUND
}

\author{
hans Janssen ${ }^{1}$, Jan CARmeliet AND Hugo Hens \\ Laboratory of Building Physics \\ Department of Civil Engineering \\ Catholic University of Leuven \\ Kasteelpark Arenberg 51 \\ 3001 Leuven \\ Belgium
}

\begin{abstract}
In this paper, the influence of soil moisture transfer on building heat loss via the ground is investigated by comparing fully coupled simulations with linear thermal simulations. The observed influences of coupling are (1) the larger amplitude of surface temperature, (2) the variation of thermal conductivity with moisture content, and (3) the advection of sensible heat by liquid transfer. In a parameter study, it is shown that these conclusions hold for a variety of climates, soils and foundation constructions. However, given the current accuracy level of standard methods, the integration of coupling effects in these calculation methods cannot be defended.
\end{abstract}

\section{KEYWORDS}

Foundation heat loss, coupled soil heat and moisture transfers, surface heat and moisture balances.

\section{INTRODUCTION}

The last few decades, a manifest evolution towards a more sustainable use of energy is taking place. Since a substantial share of the global energy budget is consumed for the heating and cooling of buildings, the building industry and building science have not been left unaffected. One of the more important developments in this particular field is the ongoing improvement of the insulating quality of the building envelope.

Most of the efforts in this evolution though have been concentrated mainly on the above grade building parts like walls and roofs, as these initially posed the biggest potential. Building heat loss via the ground has consequently gained importance. At present, this form of heat loss can no longer be considered an insignificant part of the overall building heat loss.

\section{Building heat loss via the ground and soil moisture transfer}

'Building heat loss via the ground' has been the subject of numerous analytical, numerical and experimental investigations. Comprehensive literature surveys are to be found in the works of Janssen [1], Deru [2], Bahnfleth [3] and Hagentoft [4].

The studies of Hagentoft [4] and Anderson [5] have recently been synthesised to form the European Standard ENISO 13370: Thermal performance of buildings - Heat transfer via the ground - Calculation methods. This standard introduces several expressions for calculating building heat loss via the ground, appropriate for most foundation geometries and insulation strategies.

However, most of the research on 'building heat loss via the ground' is based on one major hypothesis: none of the coupling effects between soil heat and soil moisture

\footnotetext{
${ }^{1}$ Author to whom correspondence should be addressed.

Tel: ++ 3216321347 Fax: ++ $3216321980 \quad$ E-mail: hans.janssen@bwk.kuleuven.ac.be.
} 
transfer are taken into account. Soil thermal conductivity and capacity are presumed constant in space and time. Moreover, only thermal conduction is considered as soil heat transfer mechanism. It is furthermore mostly assumed that the heat transfer at the soil surface is governed solely by the air temperature, usually in combination with a constant heat transfer coefficient. By making these assumptions, 'building heat loss via the ground' remains a linear thermal problem, and hence suitable for analytical or uncomplicated numerical analysis.

Soil moisture does nevertheless interact with soil heat transfer, through various mechanisms: (1) soil thermal conductivity and capacity are highly dependent on soil moisture content, (2) the transfer, storage and/or phase change of moisture result in a concurrent transfer and/or storage of sensible and/or latent heat, and (3) evapo(transpi)ration forms an integral part of the surface heat balance. These interactions do however turn 'building heat loss via the ground' into a non linear coupled problem.

The specific discipline of 'the influence of soil moisture transfer on building heat loss via the ground' has not been left entirely unattended to though. Farouki [6] collected experimental data on the thermal conductivity and thermal capacity of soils. The thermal conductivities of dry and wet sands can differ up to a factor ten, of dry and wet loams up to a factor five. The variations of the thermal capacity are less manifest, but it still doubles or triples from the dry to the wet state. Complementarily, Matsumoto and Iwamae [7] computed the one-dimensional transfers of heat and moisture in soil. An important variation of the moisture content was noted for the first metres under the surface. Measurements by Thomas and Rees [8] confirm these observations experimentally. Delsante [9] attributed the differences between simulations and measurements of building heat loss via the ground to the influence of soil moisture on the thermal conductivity of soil.

Bahnfleth [3] examined the influence of including solar and long wave radiation and potential evaporation in the surface heat balance on soil temperatures and building heat loss via the ground. The heat losses changed significantly when radiation or evaporation was included in the simulations. Results of Bharadwaj and Bansal [10] and Gupta et al. [11], numerically investigating the effects of the thermal and hygric boundary conditions on soil temperatures, confirm these findings.

In a very limited study Shen [12] calculated the two-dimensional coupled heat and moisture transfer in soil near a basement wall. The fully coupled equations for soil heat and moisture transfer were employed, but the heat and moisture balances at the surface were kept very simple. Two separate intervals of 15 days, one in winter and one in summer, were simulated for sand and loam soils. Although this restricted set of results remains insufficient to allow general conclusions, it was shown that the application of the uncoupled or the coupled equations for soil heat and moisture transfer leads to notably different basement wall heat losses.

More recently, Rees et al. [13] similarly analysed the influence of the water table height on the heat loss from earth-contact structures. The moisture content in the soil domain was assumed to be in hydrostatic equilibrium, no moisture flow was hence considered. Steady-state heat losses were calculated, which confined the considered coupling effects to the influence of soil moisture on the soil thermal conductivity. Though this again makes the results quite restrictive, it was clearly demonstrated that the effect of soil moisture on building heat loss via the ground is not negligible, and deserves further attention.

\section{Fully coupled calculation of building heat loss via the ground}

In this paper completely coupled calculations - employing the coupled equations for heat and moisture transfer in soils, driven by the full formulations for the heat and moisture surface balances - will be presented. Comparison with linear thermal simulations 
will allow assessing the influence of soil moisture transfer on building heat loss via the ground.

Deru [2] recently reported on a similar investigation, estimating the influence of precipitation on building heat loss via the ground. To that aim, simulations over relatively short intervals ( 8 and 16 weeks) were carried out with and without rainfall. Sinusoidal variations were assumed for the remaining atmospheric variables. In a last case, he compared results of a year-round coupled simulation with a linear simulation. He concluded that soil moisture transfer has a notable influence on building heat loss via the ground. His results are however too limited to allow generalisation.

This paper presents the final results [1] from a more comprehensive analysis: the transient transfers of heat and moisture in the soil are simulated for multiple years, so that steady-periodical solutions for the foundation's heat loss can be employed for comparison. In a first part the transport equations for coupled soil heat and moisture transfer and the expressions for the atmospheric boundary conditions will be summarily introduced. Then the coupled and the linear heat loss of an insulated basement will be compared, and the observed deviations will be clarified. A parameter analysis will allow generalising the conclusions towards different soil types, climates and foundation structures. The last part will put the observed differences in a larger perspective, by comparing them with the accuracy of current calculation methods for building heat loss via the ground.

\section{MODEL FOR COUPLED SOIL HEAT AND MOISTURE TRANSFER}

\section{Coupled heat and moisture transfer in soil}

Milly [14] adopted the Philip and de Vries [15] and de Vries [16] equations for the coupled transfer of heat and moisture in porous materials, and reformulated them to obtain the matric head $\psi$, rather than moisture content $\theta$, as the independent variable. Use of matric head $\psi$ - describing the water pressure in "meters water column" - instead of the more common capillary pressure $p_{\mathrm{c}}$ - in "Pascal" - stems from hydrology, but both are easily related: $p_{\mathrm{c}}=\psi \cdot$. I. g. A comprehensive list of symbols is included the start of the article.

$$
\begin{aligned}
& {\left[C+\theta_{\mathrm{a}}\left(L_{0}+c_{\mathrm{v}}\left(T-T_{0}\right)\right) \frac{\partial \rho_{\mathrm{v}}}{\partial T}+\left(c_{1} \rho_{1}\left(T-T_{0}\right)-\rho_{\mathrm{l}} W-c_{\mathrm{v}} \rho_{\mathrm{v}}\left(T-T_{0}\right)-\rho_{\mathrm{v}} L_{0}\right) \frac{\partial \theta}{\partial T}\right] \frac{\partial T}{\partial t}} \\
& +\left[\theta_{\mathrm{a}}\left(L_{0}+c_{\mathrm{v}}\left(T-T_{0}\right)\right) \frac{\partial \rho_{\mathrm{v}}}{\partial \psi}+\left(c_{1} \rho_{1}\left(T-T_{0}\right)-\rho_{1} W-c_{\mathrm{v}} \rho_{\mathrm{v}}\left(T-T_{0}\right)-\rho_{\mathrm{v}} L_{0}\right) \frac{\partial \theta}{\partial \psi}\right] \frac{\partial \psi}{\partial t} \\
& =\nabla^{\mathrm{T}}\left[\lambda \nabla T+\rho_{1} L D_{\psi \mathrm{v}} \nabla \psi-c_{1}\left(T-T_{0}\right) q_{\mathrm{m}}\right] \\
& {\left[\left(1-\frac{\rho_{v}}{\rho_{l}}\right) \frac{\partial \theta}{\partial \psi}+\frac{\theta_{\mathrm{a}}}{\rho_{1}} \frac{\partial \rho_{\mathrm{v}}}{\partial \psi}\right] \frac{\partial \psi}{\partial t}+\left[\left(1-\frac{\rho_{\mathrm{v}}}{\rho_{1}}\right) \frac{\partial \theta}{\partial T}+\frac{\theta_{\mathrm{a}}}{\rho_{1}} \frac{\partial \rho_{\mathrm{v}}}{\partial T}\right] \frac{\partial T}{\partial t}} \\
& =\nabla^{\mathrm{T}}\left[\left(K+D_{\psi \mathrm{v}}\right) \nabla \psi+D_{\mathrm{Tv}} \nabla T\right]+\frac{\partial K}{\partial z}
\end{aligned}
$$

The left sides of Equations (1) and (2) describe respectively the storage of heat and moisture in soil. Storage of heat can result from changes in temperature, but also from changes in matric head, via the sensible and latent heat of the moisture phase. Moisture storage can similarly result from changes in matric head and temperature, since 
the moisture content $\theta$ and the vapour density $\rho_{v}$ depend on both $\psi$ and $T$. The right sides of the equations describe the transport of heat and moisture in soil. Both transfers can be caused by gradients in temperature or in matric head. The last term in Equation (1) represents the advection of sensible heat by moisture transfer. The last term in Equation (2) indicates the moisture transfer by gravity. Empirical and theoretical models for the material properties of soils are widely employed in soil science, as measured data are commonly difficult to obtain. A more in depth elaboration on the transfer equations and the material properties can be found in [1].

\section{Heat and moisture boundary conditions}

For the heat and moisture balances at the external soil surface, the surface is assumed bare and non irrigated. Evapotranspiration and root water uptake by plants hence take no part in the transfer processes. The surface heat balance (3) thus comprises sensible heat exchange $H$, solar and long wave radiation $R_{\mathrm{t}}$, and the transfer of sensible and latent heat by evaporation $L E$ and precipitation $H P$, while the moisture balance (4) includes precipitation $P$ and evaporation $E$ :

$$
\begin{aligned}
& q_{\mathrm{h}, \mathrm{se}}=H+R_{t}+L E+H P \\
& q_{\mathrm{m}, \mathrm{se}}=E+P
\end{aligned}
$$

Values for air temperature, direct and diffuse short wave radiation, wind speed, relative humidity and vertical rain are obtained from Design Reference Years (DRY), which are commonly used for simulations of heat and moisture transfer in building components. Values for the surface properties, as albedo, emissivity, ..., are taken from literature.

At the bottom of the soil domain, a water table is assumed present. Saturation is thus imposed as hygric boundary condition. Bearing the low velocities of ground water flow in mind, a constant temperature thermal boundary condition cannot be defended. An adiabatic condition is applied instead. The transfer of sensible and latent heat over the bottom boundary, due to moisture drained to the water table boundary, needs however to be excluded from this 'no-heat-flow-condition' [14].

The foundation construction itself is not modelled explicitly, but is included as a thermal resistance between the internal atmosphere $\left(20^{\circ} \mathrm{C}\right)$ and the soil domain. Hagentoft [4] proved that this simplification does not appreciably affect the heat flows. The foundation is further assumed impermeable. The vertical boundary planes of the soil domain are presumed adiabatic and impermeable. A more exhaustive description of the boundary conditions can be found in [1].

\section{CALCULATION OBJECTS AND PROCEDURES}

For the investigation both one- and two-dimensional simulations of the heat and moisture transfer in soil are performed. The typical one-dimensional calculation object used is a $15 \mathrm{~m}$ deep soil column. The typical two-dimensional calculation object is an insulated basement of $2.5 \mathrm{~m}$ deep by $10 \mathrm{~m}$ wide with thermal transmittance $U_{\mathrm{f}}$ of $0.7 \mathrm{~W} / \mathrm{m}^{2} \mathrm{~K}$ for the floor and walls. Because of symmetry, only half of this basement needs to be modelled. The adjoining soil domain has a depth of $15 \mathrm{~m}$, and extends for $15 \mathrm{~m}$ away from the basement wall. Figure 1 illustrates the two-dimensional simulation domain and its optimised - by comparing results for different element densities - finite element discretisation.

LOAM (37\% sand - $38 \%$ silt - $25 \%$ clay) is taken as typical soil, for its average composition and hydraulic properties. These properties are determined with Rosetta [17], a prediction program based on neural networks. For the thermal properties, $80 \%$ of the sand, $35 \%$ of the silt and $5 \%$ of the clay minerals are considered quartz [18], the re- 
maining part is assumed less conductive. The most important material properties for this soil are surveyed in Figure 2.

The climate of Essen (Germany) is taken as typical climate. Design Reference Year data for this city are obtained from [19].

All one-dimensional simulations are initialised with the average air temperature and with a hydrostatic matric head profile ( $0 \mathrm{~m}$ at the water table, $-15 \mathrm{~m}$ at the surface). They are continued for 15 years to ensure a steady-periodical solution. Two-dimensional simulations are initialised with the outcomes from a steady-state initialisation run, calculating the temperature and matric head fields resulting from the foundation's heat loss and the one-dimensional deep ground temperature and matric head imposed at the soil surface. This initialisation considerably accelerates the convergence towards the steady-periodical solution. Starting from there, a 10 to 15 year interval is simulated with the transient boundary conditions, until the steady-periodical state is attained. The average of the deviations between the daily heat losses from the last and the one but last year is smaller than $0.01 \%$ for all cases simulated.

Results from one-dimensional simulations are represented as the depth profiles of monthly averaged temperatures, matric heads and moisture contents, and as a cumulative time profile of the moisture drained across the soil surface. Results from two-dimensional heat loss simulations are presented graphically as temporal curves of the instantaneous heat losses, and alphanumerically by cumulated heat losses and the steady-state and periodical thermal permeances $U$ ' and $L_{p}$ '. These are defined as:

$$
\begin{aligned}
& U^{\prime}=\frac{\text { average(building part heat loss }) / \text { area(building part) }}{\text { average }\left(\text { difference }\left(\mathrm{T}_{\mathrm{i}}-\mathrm{T}_{\mathrm{es}}\right)\right)} \mathrm{W} / \mathrm{m}^{2} \mathrm{~K} \\
& L_{\mathrm{p}}{ }^{\prime}=\frac{\text { amplitude(building part heat loss }) / \text { area(building part) }}{\text { amplitude }\left(\text { difference }\left(\mathrm{T}_{\mathrm{i}}-\mathrm{T}_{\mathrm{es}}\right)\right)} \mathrm{W} / \mathrm{m}^{2} \mathrm{~K}
\end{aligned}
$$

Note that the external surface temperature, and not the air temperature, is used in the definitions of the thermal permeances (5) and (6). Since both radiation and evaporateon contribute to the surface heat balance, the air temperature can no longer be considered the correct driving force for the foundation heat loss. The necessary averages and amplitudes are obtained by harmonical approximation with the least squares method.

\section{COMPUTATIONAL CONSIDERATIONS}

The transfer equations and boundary conditions are solved with a finite element spatial discretisation (Figure 1) and a fully implicit time stepping scheme. Since especially the boundary conditions are highly non linear, the Newton-Raphson algorithm is employed for improved convergence of the iterative procedure.

The numerically rather difficult transfer equations and boundary conditions, the large simulation domains and the long simulation intervals needed to reach the steady-periodical solution, make computational efficiency an essential concern for such coupled simulations of building heat loss via the ground.

A first measure herein is the application of a 'variable time step' algorithm. Time steps do not need to be equal at all times during simulations: at the onset of a rain event, very small time increments are necessary to allow an accurate simulation of the absorption and the drainage of the precipitation. At other times, greater time steps can be used to reduce the computation time. The time steps are hence varied proportionally to the number of iterations that were needed to arrive at convergence in the previous time step. A maximum time step, equal to the interval of the climatic data, is superimposed. 
Hagentoft [4] and Bahnfleth [3] observed that within-the-day variations of the atmospheric boundary conditions yield only slight ripples on the yearly heat loss curve, and can hence safely be ignored for linear thermal simulations of building heat loss via the ground. Whether this conclusion holds for non linear coupled simulations needs to be verified.

Therefore, results from one-dimensional and two-dimensional simulations of soil heat and moisture transfer under excitation by hourly and daily averaged climate data are compared. Results for a one-dimensional example, the LOAM column under the Essen climate, are compared in Figure 3. It can be easily observed that the use of daily averaged climate data does not notably affect the transfers of heat and moisture in soil. A small rise of the average temperatures can however be seen. Results from other soil-climate combinations confirm these findings [1].

Figure 3 also clearly demonstrates the differences between the transfers of heat and moisture in soil: while the temperature amplitude is dampened quite quickly, the moisture content variations penetrate almost to the bottom of the domain.

Figure 4 and Table 1 present the results from the two-dimensional comparison, the heat loss from the insulated basement in the LOAM soil domain under the Essen climate. It is graphically clear that the heat loss drops slightly for the daily averaged climate data, due to somewhat higher surface temperatures (Table 1), but the difference is sufficiently small to justify the use of daily instead of hourly climate data. This measure reduces the computation times for two-dimensional simulations from two weeks to two days (on a $1500 \mathrm{MHz}$ personal computer).

Large time steps in non linear simulations can however lead to errors in the heat and mass balances. Values for the thermal and hygric capacities are evaluated on a specific moment during the time step, which may not be representative for the entire step. To ensure that the heat and mass balances are respected at all times, the approach of Celia et al. [20] is generalised from isothermal transfer of liquid moisture to the coupled transfer of heat and moisture in all phases. More details are to be found in [20] and [1].

\section{THE INFLUENCE OF SOIL MOISTURE TRANSFER}

\section{Simulation results}

The bold curves in Figure 5 represent the instantaneous heat losses resulting from the fully coupled - the coupled equations for soil heat and moisture transfer and the full formulations for the surface heat and moisture balances - simulation $A$ on the insulated basement in the LOAM soil domain under the Essen climate. The fine curves in Figure 5 depict the linear thermal results $B$. In that simulation, the moisture contents are kept at their respective yearly averages from the coupled simulation. Only the variation with time is excluded, whereas the spatial variation is retained: defining a 'spatially averaged' moisture content is not straightforward, and would not add to the analysis. No moisture transfer is hence included, and thermal conduction is considered as the only heat transfer mechanism. At the surface, the air temperature governs the solely convective heat balance (' $H$ ' in Equation (3)). The alphanumerical results from both simulations are collected in Table 2.

As can be observed in Figure 5 and Table 2, particular deviations exist between the coupled and the linear results. On the whole, the coupled simulation yields higher heat losses: the basement heat loss during the heating season is $11 \%$ higher than the respective linear value. From Table 2, it can be easily concluded that these deviations arise from (1) differences in the surface heat balance (the surface temperature amplitudes differ significantly), and (2) differences in the soil heat transfer mechanisms (the steady-state and periodical thermal permeances differ significantly). Possible reasons for the deviations are hence to be sought in two fields: 
- driving force: variations in the formulation of the heat balance at the surface may lead to different soil surface temperatures, and hence to different foundation heat losses;

- heat transfer in the ground domain: the inclusion of moisture storage and transfer in the heat transfer equation will produce alternative mechanisms for the storage and transfer of heat;

Note: this distinction between the surface temperatures and soil heat transfers is however valid only if the thermal regime in the soil domain is (quasi-)linear. This condition is implicitly met for the linear simulation, by use of temporally invariant thermal properties for the solely conductive soil heat transfer. The quasi-linear behaviour of the coupled regime has been evaluated in [1]: the soil temperature amplitude decreases exponentially with depth. The distinction between surface temperature and soil heat transfer is hence allowed.

\section{Analysis of the deviations}

\section{Surface temperatures}

Kusuda and Achenbach [21] and Givoni and Katz [22] measured that the average soil surface temperature is generally almost equal to the average air temperature, whereas the amplitude of the surface temperature is usually slightly greater than that of air temperature. They conclude that short and long wave radiation and evaporation should be taken into account for a correct estimation of soil surface temperature.

The coupled and the linear average surface temperature agree quite well with the average air temperature, and are furthermore almost equal (Table 2). The overall addition of "surface" heat by inclusion of the short and long wave radiation terms is obviously compensated by heat loss through evaporation. Since the coupled and the linear average surface temperature are equal, they cannot explain the noted deviations between the coupled and the linear basement heat loss.

The coupled amplitude of the surface temperature is slightly larger than that of air temperature, in accordance with the observations of [21, 22]. The reverse is true for the linear case. Far more meaningful though is the difference between both: the coupled amplitude is $22.5 \%$ bigger than the linear value. Assuming equal thermal permeances for the soil domain, the coupled simulation will hence result in a $22.5 \%$ higher peak value in heat loss. This gives rise to a first major source of deviation between the coupled and the linear simulation of building heat loss via the ground: a difference in the driving force, the soil surface temperature.

\section{Soil heat transfer}

Apart from differences in soil surface temperature, the deviations between the coupled and the linear simulation are also brought about by differences in the storage and transfer of heat in the soil medium: the coupled thermal permeances, both steady-state and periodical, are bigger than their respective linear values.

To particularise these differences in soil heat transfer, additional simulations with a stepwise increasing degree of coupling are performed. These simulations are of a more academic nature: the daily moisture contents from simulation A are imposed instead of solving the moisture transfer equations explicitly, and the surface heat balance is simplified to convective heat exchange driven by a harmonically varying air temperature (average: $282.45 \mathrm{~K}$, amplitude: $9.5 \mathrm{~K}$, chosen so to mimic the coupled surface temperature results) with a constant heat transfer coefficient of $23 \mathrm{~W} / \mathrm{m}^{2} \mathrm{~K}$. This simplification yields less fluctuation in the heat loss curves, which makes displaying the results notably clearer. 
Simulation $C$ represents the bare minimum: no coupling effects are taken into account. Year-averaged moisture contents are imposed - implying temporally invariable thermal properties - and only conduction is considered as soil heat transfer mechanism. Even the effect of latent heat transfer by thermal vapour diffusion on the soil's thermal conductivity is excluded, rendering simulation $\mathrm{C}$ a rather academic case. This specific coupling effect can never be avoided in the experimental determination of soil thermal conductivity [16], which thus always results in 'effective thermal conductivities'. Its influence is illustrated in Figure 2, depicting both the 'basic' and the 'effective' thermal conductivity of SAND. The simulation $C$ differs from the linear reference simulation $B$ in this particular aspect: basic conductivities are applied in C, while effective conductivities were used for B.

Simulation $\mathrm{D}$ also employs the effective thermal conductivities. In simulation $\mathrm{E}$, variations of thermal conductivity with moisture content are included, whereto simulation $F$ adds the variations of thermal capacity. Simulation $G$ inserts the remaining heat transfer due to vapour transfer. Ultimately simulation $\mathrm{H}$ integrates the heat transfer resulting from liquid transfer.

The simulation results for the basement floor are given graphically in Figure 6 and alphanumerically in Table 3. It can be noted in Table 3 that the $\mathrm{A}$ and $\mathrm{H}$ thermal permeances agree well, as do the $B$ and D permeances. The simplified moisture transfer and boundary conditions do hence not affect the analysis. The results for the wall are similar, but less striking. Figure 6 makes it clear that the differences between the coupled and the linear soil heat transfer are to be attributed to two main coupling effects: the variation of the thermal conductivities with moisture content (simulations $D \& E$ ) and the transfer of sensible heat by liquid moisture transfer (simulations $G \& H$ ). The third notable effect, the influence of latent heat transfer by thermal vapour diffusion (simulations $C \& D$ ), can be judged academic, since it is generally included by use of the effective soil thermal conductivity.

\section{Conclusion}

In this article, a fully coupled simulation of building heat loss via the ground has been performed, which has been compared with results from a linear thermal simulation. That way, a generally accepted postulate in the field of building heat loss via the ground has been falsified: the influence of soil moisture transfer on building heat loss via the ground is indeed not negligible.

An in depth analysis of the results learned that the influence of soil moisture transfer on building heat loss via the ground can be brought back to three main coupling effects:

- the increased amplitude of the soil surface temperature, due to the inclusion of evaporation and radiation in the surface heat balance;

- the variation of the thermal properties with soil moisture content;

- the advection of sensible heat with liquid moisture transfer;

A fourth coupling effect, the latent heat transfer by thermal vapour diffusion, is commonly included in all, even linear, simulations, by application of effective soil thermal conductivities.

\section{PARAMETER STUDY}

The coupled heating season heat loss is $11 \%$ higher than the linear heat loss, a not insignificant influence of soil moisture transfer on building heat loss via the ground. In order to allow more comprehensive conclusions, a parameter study is performed, varying the climate (Munchen, Bremerhaven), the precipitation amount (0.5 P, 1.5 P), the soil type (SAND, SILT, CLAY, sand; the first three are defined analogously to LOAM; 'sand' represents soils with very high sand contents), the thermal resistance of the basement walls and floor $\left(0.35 \mathrm{~W} / \mathrm{m}^{2} \mathrm{~K}, 5.4 \mathrm{~W} / \mathrm{m}^{2} \mathrm{~K}\right)$, the basement width $(8 \mathrm{~m}, 15 \mathrm{~m})$ and the shape of the foundation (ground floor). 
Variations of the precipitation amount $\mathrm{P}$ are included to extend the set of available climates. $\mathrm{P}$ is however the only climatic parameter varied, as an auxiliary analysis revealed that all other parameters - albedo, emissivity, roughness height, cloud cover, water table depth, ... - had a lesser influence on the transfers of heat and moisture in the soil domain [1].

The set of simulations A-H is carried out for all considered cases. Their results are not explicitly included, but they confirm our conclusions on the deviations between the coupled and the linear simulation of building heat loss via the ground.

The resulting differences between the coupled and the linear heating season heat loss are represented in Figure 7. It is apparent from this graph that 'soil type' and 'basement width' do not affect the influence of coupling significantly: the relative differences between coupled and linear heat loss do not change appreciably. This is evident for the basement width: this parameter cannot have a real impact on the surface temperature's amplitude, nor on the variations of the thermal conductivity, nor on the advective heat transfer. A similar conclusion holds for the soil type as well though: from the related one-dimensional simulations [1] it can be observed that the transfers of heat and moisture in the different soils are similar, despite their differences in thermal and hygric properties. It appears that ultimately the climate governs the hygrothermal behaviour of the soil. The significant effect of climate and precipitation amount on the coupling influence at the other hand (see Figure 7), confirm this deduction.

All in all, it can be concluded that the coupled simulation of building heat loss via the ground increases [1]:

- the heating season heat loss

- the surface temperature amplitude

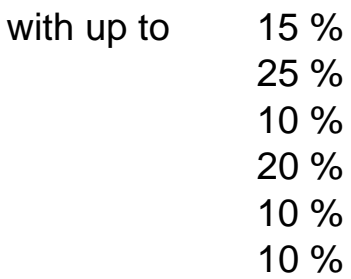

- the steady state floor thermal permeance $10 \%$

- the periodical floor thermal permeance $20 \%$

- the steady state wall thermal permeance $10 \%$

- the periodical wall thermal permeance

$10 \%$

when compared to their respective linear values. Such differences cannot be regarded as insignificant: soil moisture transfer thus has an indisputable influence on building heat loss via the ground, via the surface temperature's amplitude, the variation of the thermal conductivity, and the advective heat transfer.

\section{THE LARGER PERSPECTIVE}

In the previous paragraph, it was shown that the inclusion of coupling effects in simulations of building heat loss via the ground leads to notably different results. Their significance 'in the big picture' will be assessed by comparing the observed deviations with the accuracy of the current European Standard ENISO 13370 for building heat loss via the ground.

\section{Limitations of current study}

As background to that judgement, the limitations imposed and the simplifications accepted for this investigation are summarised. First and foremost, all simulations have been carried out two-dimensionally, primarily to keep the computation times within feasible limits. Possible effects from three-dimensional soil heat or moisture transfer were neglected.

Secondly, a bare soil surface was assumed for the formulation of the surface heat and moisture balances. Evapotranspiration and root water uptake were disregarded. Furthermore, free field conditions were employed, neglecting any interference from the above grade building. Shadowing, long wave radiation exchange, ... were not accounted for.

And thirdly, only homogeneous soil domains have been considered. Stratification or highly permeable backfills were not taken into account. 
Moreover, coupled and linear heat losses were compared for a very conservative case, since the basement was always assumed to be fully conditioned. While this may hold for ground floors, it does not need to be true for basements. The influences of coupling are most likely less important for unheated basements.

\section{Current potential accuracy}

In order to assess the current potential accuracy of standard calculation methods for building heat loss via the ground, the steady-state and the periodical thermal transmittances of some ground floors and basements as calculated with ENISO 13370, are compared to results from linear thermal simulations in three $(U)$ and two $\left(L_{p}\right)$ dimensions. In these linear simulations the ground domain is assumed to have one thermal conductivity $(1.75 \mathrm{~W} / \mathrm{mK})$ and thermal capacity $\left(2.5 \mathrm{MJ} / \mathrm{m}^{3} \mathrm{~K}\right)$. These simulations hence differ from the linear simulations performed earlier in this work.

The results of this comparison are collected in Table 4. It can be observed that the deviations between the ENISO 13370 and the simulated thermal permeances are in the same order of magnitude as the deviations caused by coupling effects.

A further and even more important source of inaccuracy lays in the determination of the soil thermal properties. For the coupled simulations, the relation $\lambda(\theta)$ was assumed known and accurate, which in reality is generally not the case. ENISO 13370 gives 1.5 $\mathrm{W} / \mathrm{mK}$ and $2.0 \mathrm{~W} / \mathrm{mK}$ as representative values for clay or silt and sand respectively. Presupposing that the soil type is known, these values are not necessarily accurate. For the SAND defined in this work, the maximal thermal conductivity is $2.26 \mathrm{~W} / \mathrm{mK}$. At its average moisture content under the climate of Essen (Figure 3), the thermal conductivity decreases to $1.65 \mathrm{~W} / \mathrm{mK}$ though. This value is furthermore influenced by the climate and the surface properties, as they determine the hygrothermal response of the soil and thus the thermal conductivity. An accurate assessment of thermal conductivity is hence not feasible. Use of the conservative $1.5 \mathrm{~W} / \mathrm{mK}$ and $2 \mathrm{~W} / \mathrm{mK}$ values does however introduce deviations far greater than those due to coupling phenomena. Similar arguments hold for the soil thermal capacity.

It is hence demonstrated that the inaccuracies of the ENISO 13370 - caused by the approximating nature of the analytical expressions and by deviations between the real and the standard values for the soil thermal properties - are considerably larger than the influences of coupling. The implementation of the coupling effects in standard foundation heat loss calculation methods hence cannot be defended, as such implementation would not contribute appreciably to the ultimate accuracy.

Such implementation would furthermore introduce numerous new parameters - surface properties as albedo, emissivity, roughness length, ...; climate parameters as precipitation amount and distribution, cloudiness, ... ; heterogeneous material properties for the soils - into the calculation. Only some of those will be available with the precision needed to add surplus accuracy to simulations of building heat loss via the ground.

\section{CONCLUSIONS}

In this paper, the influence of soil moisture transfer on building heat loss via the ground has been analysed by comparing coupled simulations with linear thermal simulations. Significant deviations between both were observed, and they were attributed to (1) the greater amplitude of the coupled soil surface temperature's amplitude, (2) the variation of the thermal conductivity with the moisture content, and (3) the advection of sensible heat by liquid moisture transfer.

Given the current accuracy of the ENISO 13370, it has to be concluded however that integration of the coupling effects in standard calculation methods for building heat loss via the ground can at present not be defended. 


\section{NOMENCLATURE}

C : volumetric thermal capacity $\left(\mathrm{J} / \mathrm{m}^{3} \cdot \mathrm{kg}\right)$

$\mathrm{C}_{\mathrm{l}} \quad$ : specific heat of water $(\mathrm{J} / \mathrm{kg} \cdot \mathrm{K})$

$\mathrm{C}_{\mathrm{v}} \quad$ : specific heat of vapour $(\mathrm{J} / \mathrm{kg} \cdot \mathrm{K})$

$D_{\mathrm{TV}} \quad$ : thermal vapour diffusivity $(\mathrm{m} / \mathrm{s})$

$D_{\psi v} \quad$ : hydraulic vapour diffusivity $(\mathrm{m} / \mathrm{s})$

E : amount of evaporation $\left(\mathrm{kg} / \mathrm{m}^{2} \cdot \mathrm{s}\right)$

$H$ : heat exchange by convection $\left(\mathrm{W} / \mathrm{m}^{2}\right)$

$H P$ : heat supply by precipitation $\left(\mathrm{W} / \mathrm{m}^{2}\right)$

$K \quad$ : hydraulic conductivity $(\mathrm{m} / \mathrm{s})$

$L \quad$ : heat of vaporisation of water $(\mathrm{J} / \mathrm{kg})$

$L_{0} \quad: L$ at $T_{0}(\mathrm{~J} / \mathrm{kg})$

$L_{p} \quad$ : periodical thermal transmittance $(\mathrm{W} / \mathrm{mK})$ (inside air to outside air)

$L_{p}{ }^{\prime} \quad$ : periodical thermal permeance $\left(\mathrm{W} / \mathrm{m}^{2} \mathrm{~K}\right)$ (inside air to outside surface)

LE : heat exchange by evaporation $\left(\mathrm{W} / \mathrm{m}^{2}\right)$

$n \quad$ : porosity (-)

$P \quad:$ amount of precipitation $\left(\mathrm{kg} / \mathrm{m}^{2} \cdot \mathrm{s}\right)$

$p_{c} \quad$ : capillary pressure $(\mathrm{Pa})$

$q_{\mathrm{m}} \quad:$ moisture flux $(\mathrm{kg} / \mathrm{s})$

$q_{\mathrm{h}, \mathrm{se}} \quad$ : heat flow into soil $\left(\mathrm{W} / \mathrm{m}^{2}\right)$

$q_{\mathrm{m}, \mathrm{se}} \quad$ : water drainage into the soil $\left(\mathrm{kg} / \mathrm{m}^{2} \cdot \mathrm{s}\right)$

$R_{\mathrm{t}} \quad$ : net radiation $\left(\mathrm{W} / \mathrm{m}^{2}\right)$

$t \quad$ : time (s)

$T \quad$ : temperature $(\mathrm{K})$

$T_{0} \quad$ : reference temperature $(\mathrm{K})$

$T_{\mathrm{e}} \quad$ : air temperature $(\mathrm{K})$

$T_{\text {se }} \quad$ : surface temperature $(\mathrm{K})$

$U \quad$ : steady-state thermal transmittance $\left(\mathrm{W} / \mathrm{m}^{2} \mathrm{~K}\right)$ (inside air to outside air)

$U^{\prime} \quad$ : steady-state thermal permeances $\left(\mathrm{W} / \mathrm{m}^{2} \mathrm{~K}\right)$ (inside air to outside surface)

$U_{f} \quad:$ thermal transmittance $\left(\mathrm{W} / \mathrm{m}^{2} \mathrm{~K}\right)$ of foundation structure

$W \quad$ : heat of wetting $(\mathrm{J} / \mathrm{kg})$

$z \quad$ : depth $(\mathrm{m})$ (downward positive)

$\theta \quad$ : moisture content $\left(\mathrm{m}^{3} / \mathrm{m}^{3}\right)$

$\lambda \quad$ : effective thermal conductivity $(\mathrm{W} / \mathrm{m} \cdot \mathrm{K})$

$\rho_{1} \quad:$ liquid density $\left(\mathrm{kg} / \mathrm{m}^{3}\right)$

$\rho_{v} \quad$ : vapour density $\left(\mathrm{kg} / \mathrm{m}^{3}\right)$

$\psi \quad$ : matric head $(\mathrm{m})$

\section{ACKNOLEDGEMENTS}

A large part of this research was funded by the Flemish Institute for the Promotion of Industrial Scientific and Technological Research. Their contribution is gratefully acknowledged.

\section{REFERENCES}

[1] Janssen $\mathrm{H}$. The influence of soil moisture transfer on building heat loss via the ground. Doctoral Dissertation 2002, Catholic University of Leuven, Belgium. http://www.kuleuven.ac.be/bwf/eng/publications_01.htm

[2] Deru M. A model for ground-coupled heat and moisture transfer from buildings. Doctoral Dissertation 2001, Colorado State University, United States.

[3] Bahnfleth W.P. A three-dimensional numerical study of slab-on-grade heat transfer, Doctoral Dissertation 1989, University of Illinois, United States. 
[4] Hagentoft C.-E. Heat loss to the ground from a building. Doctoral Dissertation 1988, Lund University of Technology, Sweden.

[5] Anderson B.R. Calculation of the steady-state heat transfer through a slab-onground floor. Building and Environment 1991;26:405-415.

[6] Farouki O.T. Evaluation of methods for calculating soil thermal conductivity. CRREL Report 82-8 1982, United States.

[7] Matsumoto M., Iwamae A. An analysis of temperature and moisture variation in the ground under natural climatic conditions. Energy and Buildings 1988;11:221-237.

[8] Thomas H.R., Rees S.W. The thermal performance of ground floor slabs-a full scale in-situ experiment. Building and Environment 1999;34:139-164.

[9] Delsante A.E. A comparison between measured and calculated heat losses through a slab-on-grade floor. Building and Environment 1990;25:25-31.

[10] Bharadwaj S.S., Bansal N.K. Temperature distribution inside ground for various surface conditions. Building and Environment 1981;16:183-192.

[11] Gupta S.C., Radke J.K., Larson W.E. Predicting temperature of bare and residue covered soils with and without a corn crop. Soil Science Society of America Journal 1981;45:405-412.

[12] Shen L.S. An investigation of transient, two-dimensional coupled heat and moisture flow in soils. Doctoral Dissertation 1986, University of Minnesota, United States.

[13] Rees S.W., Zhou Z., Thomas H.R. The influence of soil moisture content variations on heat losses from earth-contact structures: an initial assessment. Building and Environment 2001;36:157-165.

[14] Milly P.C.D. The coupled transport of water and heat in a vertical soil column under atmospheric excitation. Doctoral Dissertation 1980, Massachusetts Institute of Technology, United States.

[15] Philip J.R., de Vries D.A. Moisture movement in porous materials under temperature gradients. Transactions American Geophysical Union 1957; 38:222-232.

[16] de Vries D.A. Simultaneous transfer of heat and moisture in porous media. Transactions American Geophysical Union 1958;39:909-916.

[17] Schaap M.G., Leij F.J., van Genuchten M.Th. Neural network analysis for hierarchical prediction of soil hydraulic properties. Soil Science Society of America Journal 1998;62:847-855.

[18] Tarnawski V.R., Wagner B., Webber J., Pettipas L. Optimization of soil mineralogical composition for predicting soil thermal conductivity. In: Proceedings of the international symposium on Physics, Chemistry, and Ecology of Seasonally Frozen Soils, June 10-12 1997, Fairbanks, United States.

[19] Grunewald J. Diffusiver und konvektiver Stoff- und Energietransport in kapillarporösen Baustoffen. Doctoral Dissertation 1997, Technische Universität Dresden, Germany (in German).

[20] Celia M.A., Bouloutas E.T., Zarba R.L. A general mass-conservative numerical solution for the unsaturated flow equation. Water Resources Research 1990;26:1483-1496.

[21] Kusuda T., Achenbach P.R. Earth temperature and thermal diffusivity at selected stations in the United States. ASHRAE Transactions 1965;71:61-75.

[22] Givoni B., Katz L. Earth temperatures and underground buildings. Energy and Buildings 1985;8:15-25. 
Table 1: Alphanumerical results for the hourly and the daily simulation.

\begin{tabular}{ccccccc}
\hline $\begin{array}{c}\text { Climate data } \\
\text { interval }\end{array}$ & $\begin{array}{c}\boldsymbol{U}^{\prime} \text { floor } \\
\left(\mathbf{W} / \mathbf{m}^{2} \mathbf{K}\right)\end{array}$ & $\begin{array}{c}\boldsymbol{L}_{\mathbf{p}} \text { ' floor } \\
\left(\mathbf{W} / \mathbf{m}^{2} \mathbf{K}\right)\end{array}$ & $\begin{array}{c}\boldsymbol{U}^{\prime} \text { wall } \\
\left(\mathbf{W} / \mathbf{m}^{2} \mathbf{K}\right)\end{array}$ & $\begin{array}{c}\boldsymbol{L}_{\mathrm{p}}{ }^{\prime} \text { wall } \\
\left(\mathbf{W} / \mathbf{m}^{2} \mathbf{K}\right)\end{array}$ & $\begin{array}{c}\boldsymbol{T}_{\text {es }} \text { avg } \\
(\mathbf{K})\end{array}$ & $\begin{array}{c}\boldsymbol{T}_{\text {es }} \text { amp } \\
(\mathbf{K})\end{array}$ \\
\hline hourly sim & 0.1848 & 0.0229 & 0.4372 & 0.3185 & 282.11 & 9.03 \\
daily sim & 0.1846 & 0.0224 & 0.4374 & 0.3175 & 282.47 & 9.25 \\
\hline
\end{tabular}

Table 2: $\quad$ Alphanumerical results for the coupled and the linear simulation.

\begin{tabular}{|c|c|c|c|c|c|c|}
\hline & \multicolumn{2}{|c|}{ Coupled A } & \multicolumn{2}{|c|}{ Linear B } & \multicolumn{2}{|c|}{ Difference (\%) } \\
\hline & floor & wall & floor & wall & Floor & wall \\
\hline total heat loss (MJ/year) & 310.9 & 368.4 & 287.7 & 347.5 & 8.1 & 6.0 \\
\hline heating season* heat loss (MJ/year) & 151.6 & 245.0 & 140.1 & 216.5 & 8.2 & 13.2 \\
\hline thermal permeance $U^{\prime}\left(\mathrm{W} / \mathrm{m}^{2} \mathrm{~K}\right)$ & 0.185 & 0.437 & 0.171 & 0.412 & 8.2 & 6.1 \\
\hline thermal permeance $L_{\mathrm{p}}{ }^{\prime}\left(\mathrm{W} / \mathrm{m}^{2} \mathrm{~K}\right)$ & 0.022 & 0.317 & 0.019 & 0.303 & 15.8 & 4.6 \\
\hline average surface temperature $T_{\text {es }}(\mathrm{K})$ & \multicolumn{2}{|c|}{282.47} & \multicolumn{2}{|c|}{282.46} & \multicolumn{2}{|c|}{0.0} \\
\hline $\begin{array}{l}\text { amplitude surface temperature } T_{\text {es }} \\
\text { (K) }\end{array}$ & \multicolumn{2}{|c|}{9.25} & \multicolumn{2}{|c|}{7.55} & \multicolumn{2}{|c|}{22.5} \\
\hline average air temperature $T_{e}(K)$ & \multicolumn{2}{|c|}{282.61} & \multicolumn{2}{|c|}{282.61} & & \\
\hline amplitude air temperature $T_{e}(K)$ & \multicolumn{2}{|c|}{8.14} & \multicolumn{2}{|c|}{8.14} & & \\
\hline
\end{tabular}

* heating season: 1 October till 31 March

Table 3: $\quad$ Alphanumerical results for the $\mathrm{C}-\mathrm{H}$ additional simulations.

\begin{tabular}{ccccccccc}
\hline & A & B & C & D & E & F & G & H \\
\hline$U_{\text {'floor }}\left(\mathbf{W} / \mathbf{m}^{2} \mathbf{K}\right)$ & 0.1846 & 0.1711 & 0.1648 & 0.1707 & 0.1744 & 0.1749 & 0.1750 & 0.1836 \\
$L_{\text {p'floor }}\left(\mathbf{W} / \mathbf{m}^{2} \mathbf{K}\right)$ & 0.0224 & 0.0190 & 0.0182 & 0.0192 & 0.0208 & 0.0191 & 0.0191 & 0.0226 \\
\hline
\end{tabular}

Table 4: $\quad$ Comparison of the ENISO 13370 and the simulated permeances.

\begin{tabular}{|c|c|c|c|c|c|c|c|}
\hline 5 & Building part & $\begin{array}{c}U^{*}(E N) \\
\left(W / m^{2} K\right)\end{array}$ & $\begin{array}{l}L_{p}(E N) \\
(W / m K)\end{array}$ & $\begin{array}{l}U \text { (num.) } \\
\text { (W/m²K) }\end{array}$ & $\begin{array}{c}L_{p} \text { (num.) } \\
\text { (W/mK) }\end{array}$ & $\begin{array}{c}\text { difference } \\
\text { U (\%) }\end{array}$ & $\begin{array}{c}\text { difference } \\
L_{p}(\%)\end{array}$ \\
\hline \multirow{2}{*}{ 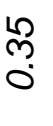 } & Basement & 0.216 & 0.435 & 0.240 & 0.491 & -10.2 & -11.5 \\
\hline & ground floor & 0.220 & 0.263 & 0.222 & 0.212 & -0.9 & 24.3 \\
\hline \multirow{2}{*}{$\frac{0}{0}$} & Basement & 0.328 & 0.728 & 0.373 & 0.848 & -12.2 & -14.1 \\
\hline & ground floor & 0.332 & 0.434 & 0.332 & 0.356 & 0.2 & 21.9 \\
\hline \multirow{2}{*}{ 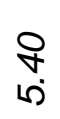 } & Basement & 0.700 & 2.032 & 0.876 & 2.586 & -20.1 & -21.4 \\
\hline & ground floor & 0.626 & 1.094 & 0.648 & 0.934 & -3.4 & 17.2 \\
\hline
\end{tabular}

* $U$ and $L_{p}$ are related to the air temperature, not the surface temperature 
FIGURE 1: Dimensions and discretisation of the typical basement simulation domain.

FIGURE 2: Water retention curve, hydraulic conductivity, specific heat and thermal conductivity for LOAM, SAND, SILT and CLAY ('pF' is defined as log $(-\psi))$. The thermal conductivity of SAND is illustrated including (normal line) and excluding (thin line) the latent heat transfer by thermal vapour diffusion.

FIGURE 3: Monthly (January, April, July and October) averaged temperatures, matric heads and moisture contents and cumulative drainage profile for the LOAM column under the Essen climate.

FIGURE 4: Daily averaged hourly and daily results for the instantaneous heat loss through the basement wall and floor, for the insulated basement in the LOAM soil under the Essen climate.

FIGURE 5: Coupled and linear basement wall and floor heat losses for the insulated basement in the LOAM soil under the Essen climate.

FIGURE 6: Heat losses through the basement floor for the insulated basement in the LOAM soil from simulations $C, D, E, F, G$ and $H$.

FIGURE 7: Differences between the coupled and the linear heating season heat loss for all cases considered in the parameter study. 
FIGURE 1:

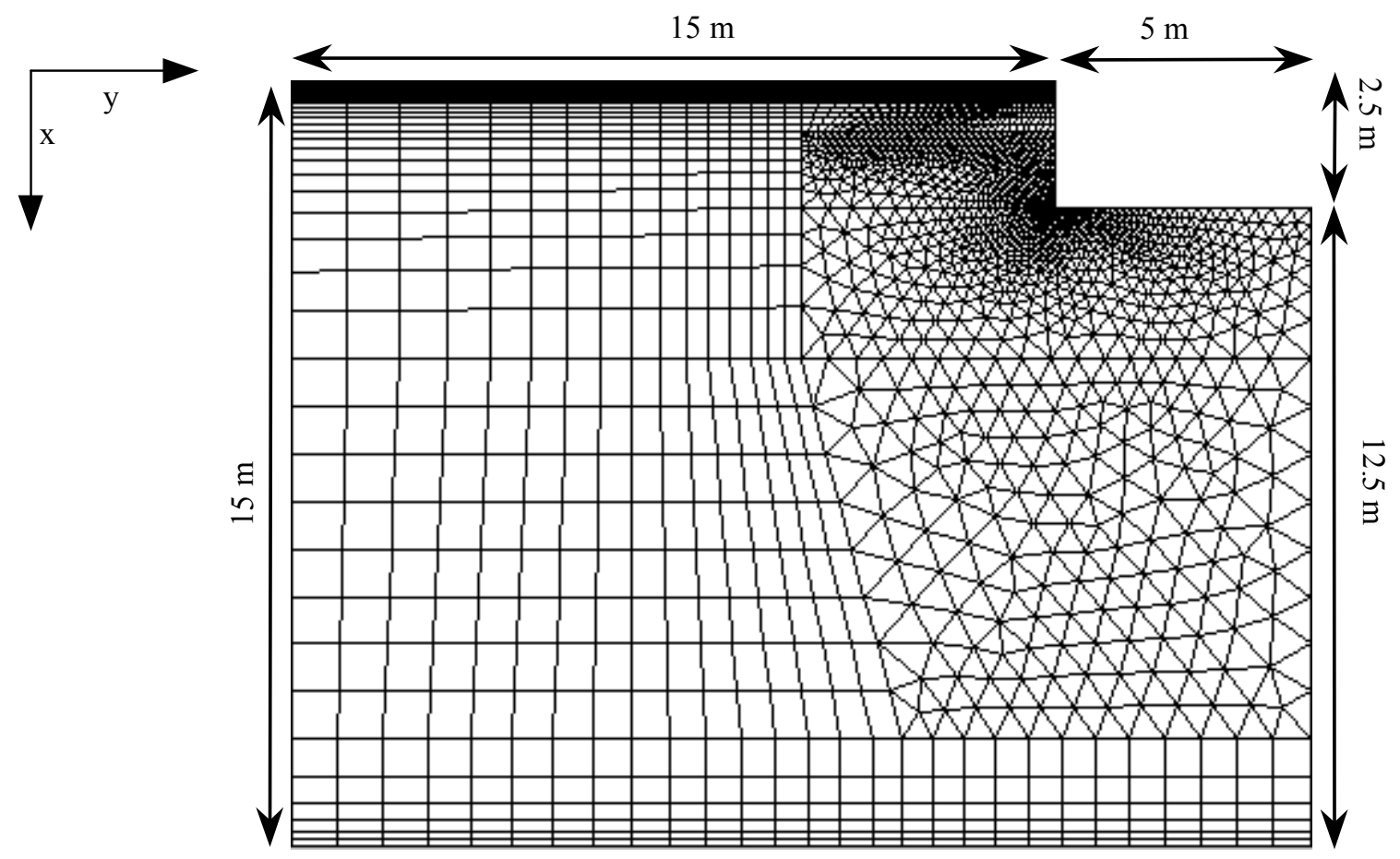

FIGURE 2:
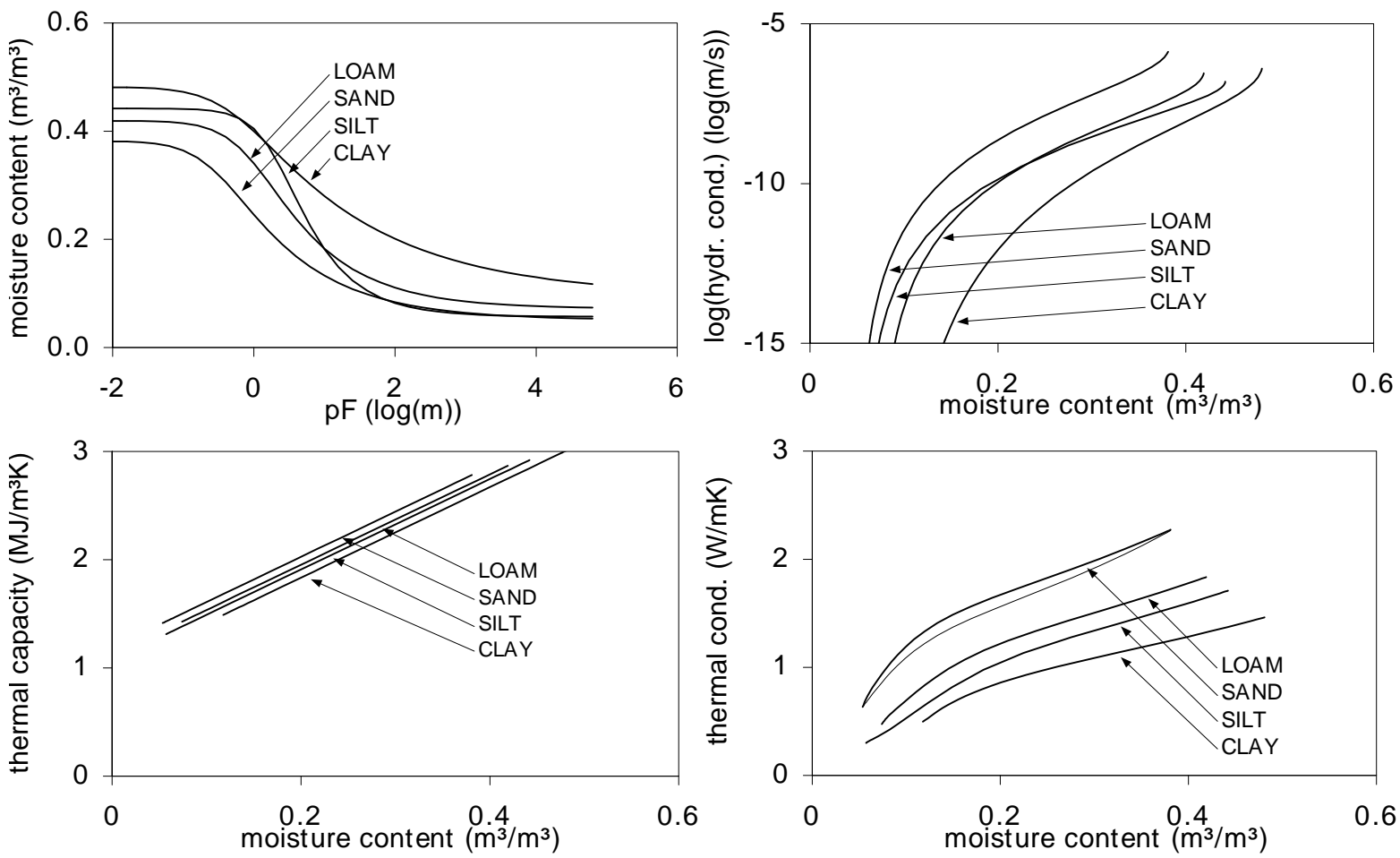
FIGURE 3:
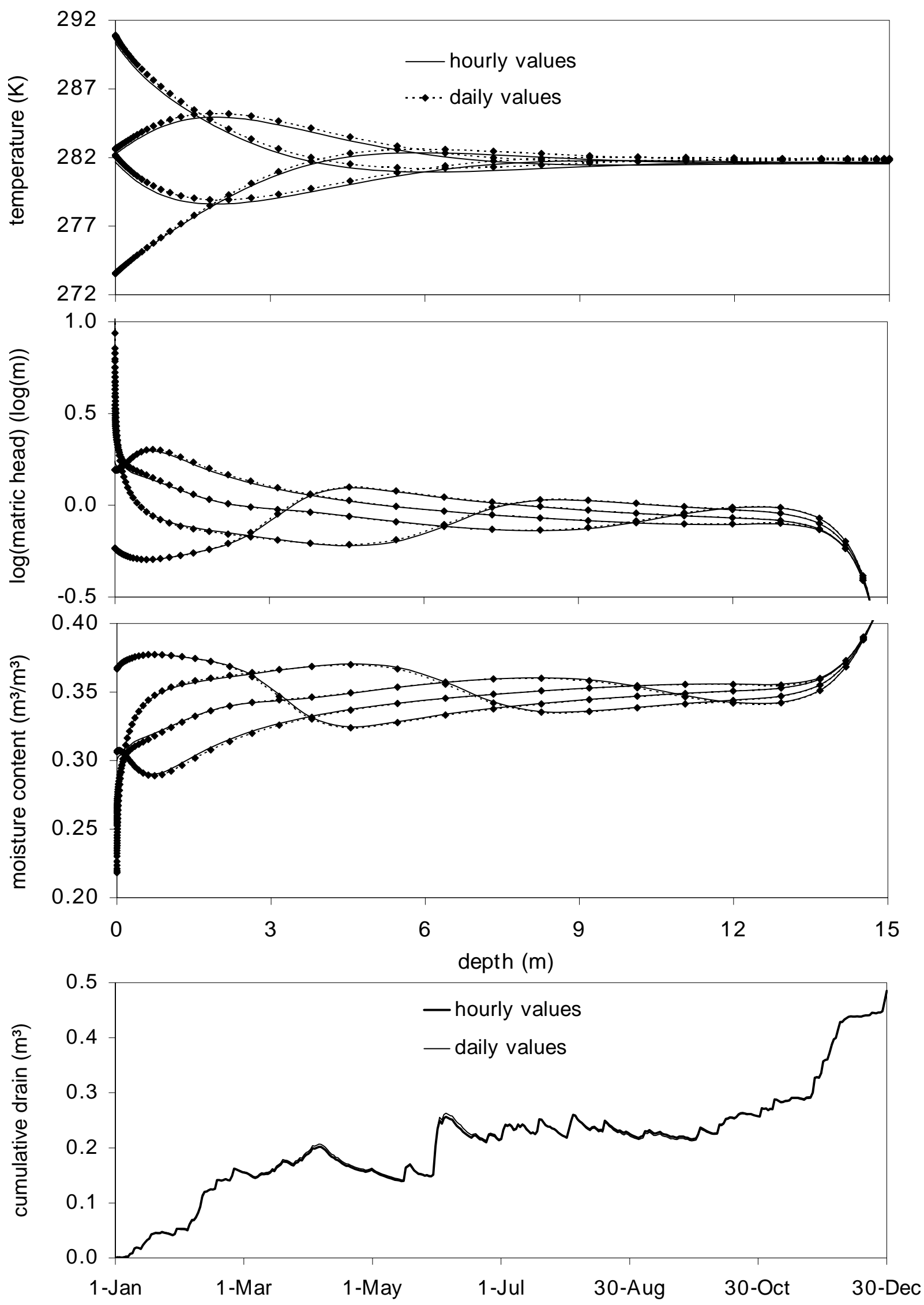
FIGURE 4:

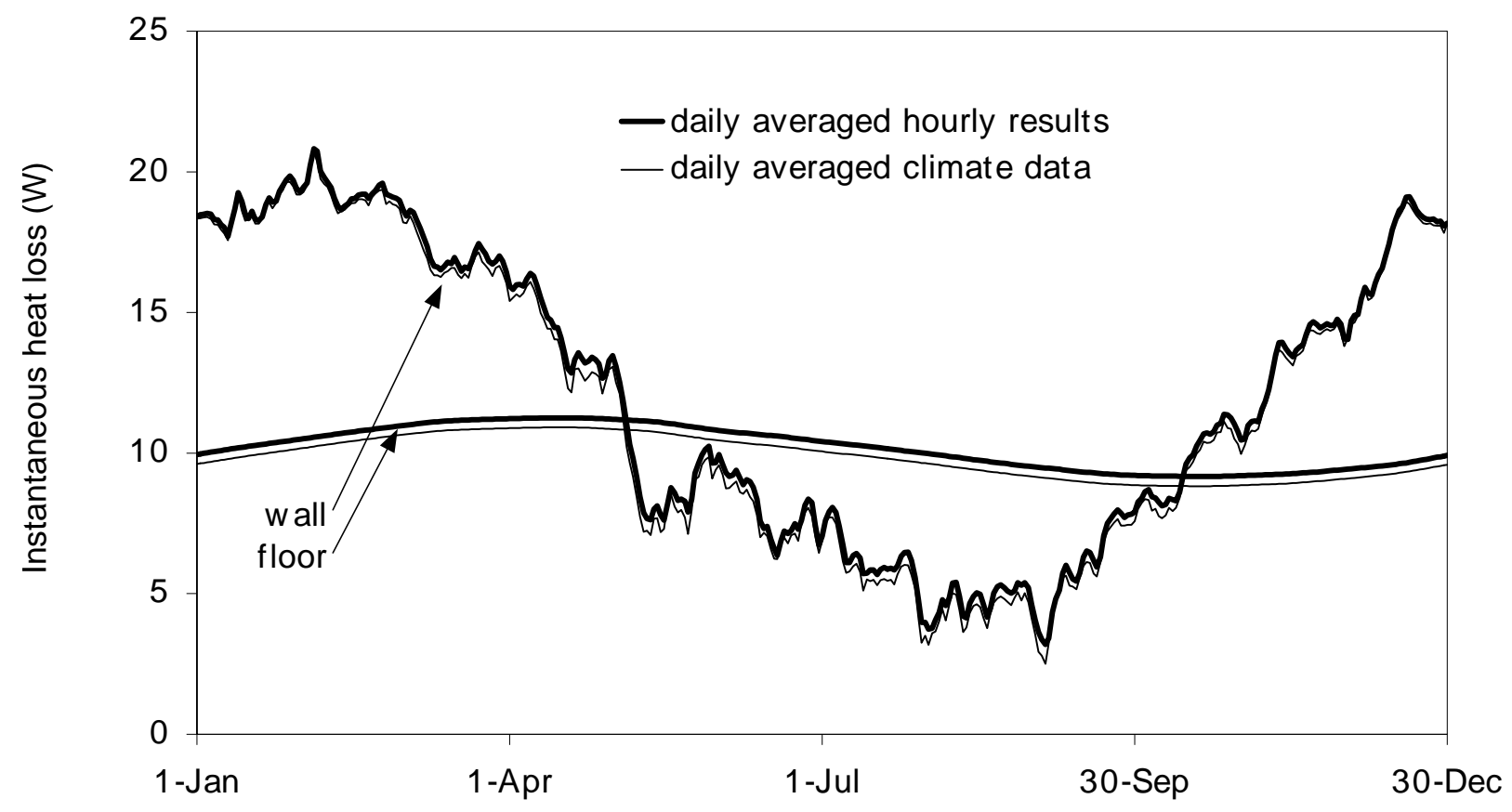

FIGURE 5:

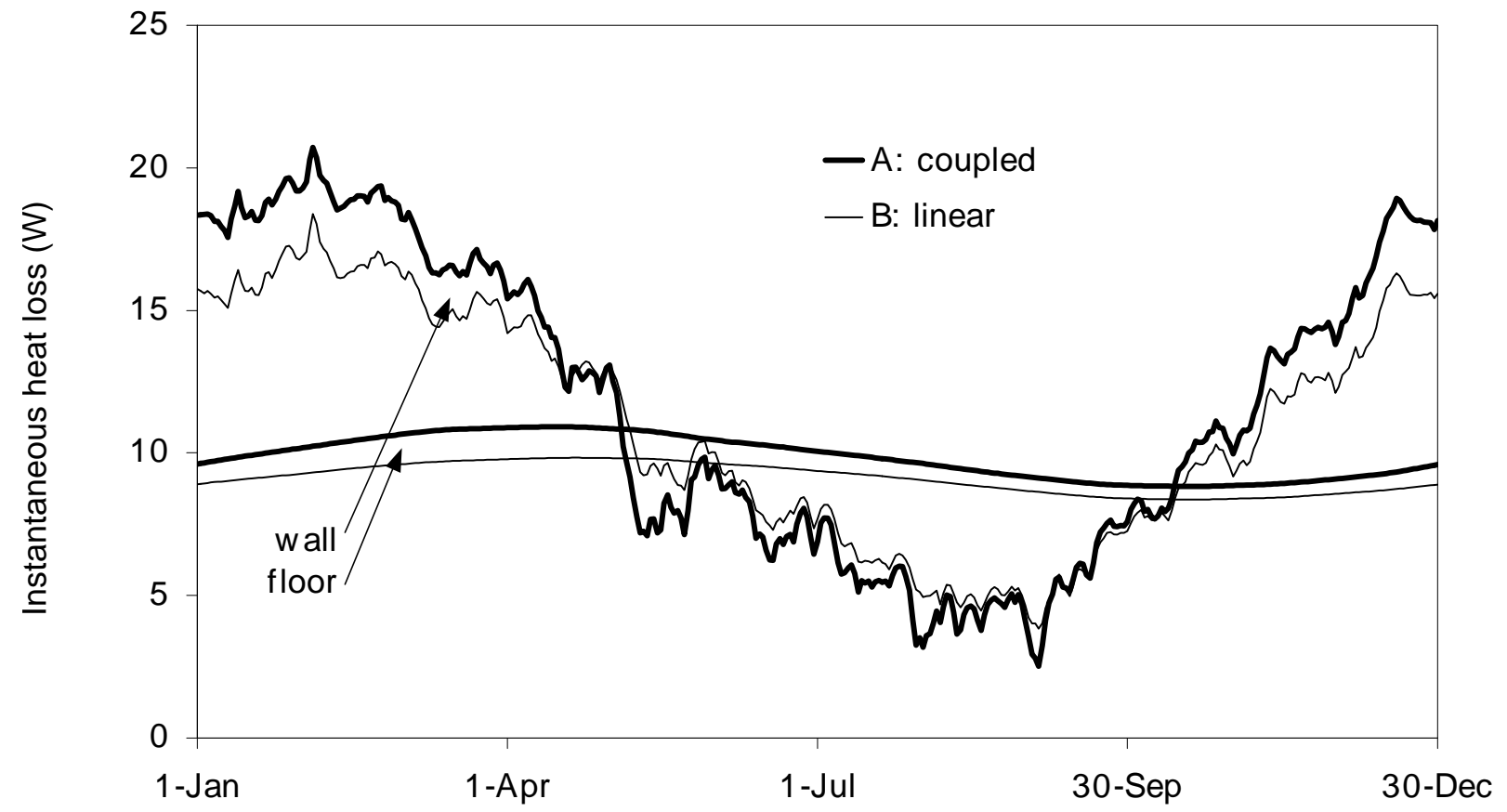


FIGURE 6:

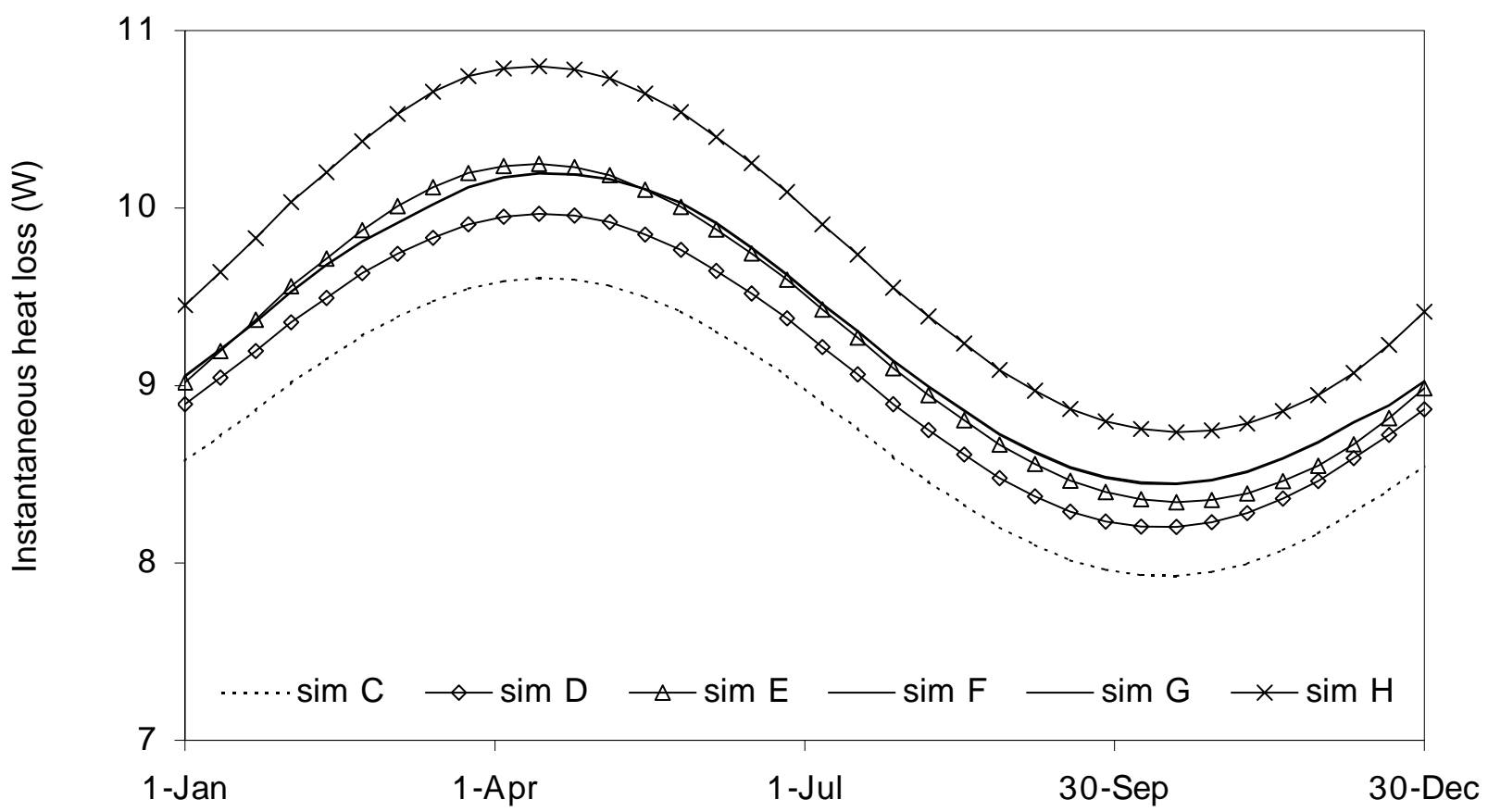

FIGURE 7:

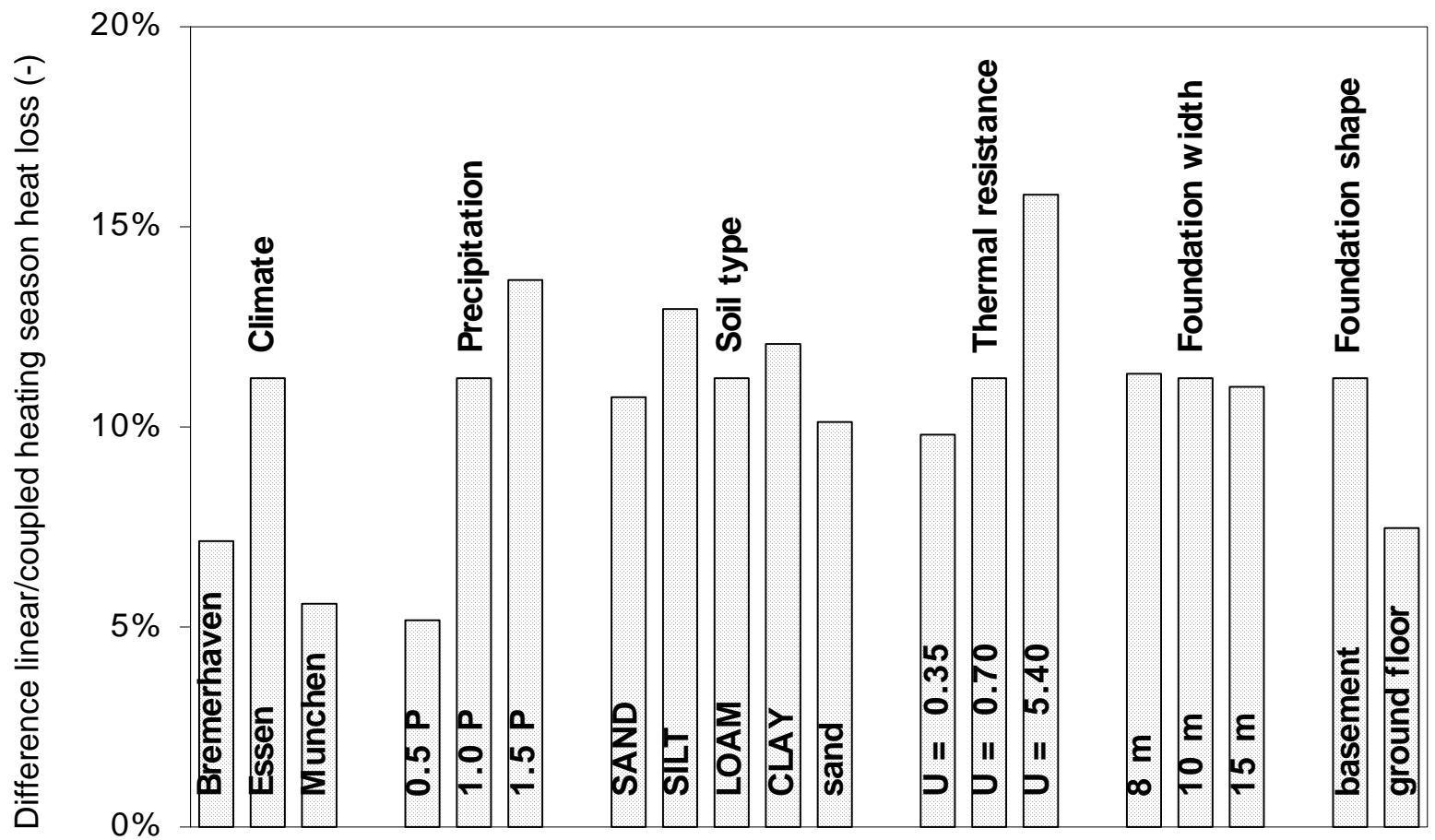




\section{Biographies}

Hans Janssen recently earned his Ph.D. at the Catholic University of Leuven, 2002, with highest distinction, on "The influence of soil moisture transfer on building heat loss via the ground". At present, he works as a research associate at the Laboratory of Building Physics, Department of Civil Engineering, Catholic University of Leuven. His current topics of interest focus on the transfer of heat, air, moisture and salt in building materials and their related mechanical effects, with an emphasis on the numerical modelling of these phenomena.

Professor Jan Carmeliet earned his Ph.D. at the Katholieke Universiteit Leuven, 1992 with highest distinction, on "Durability of fibre-reinforced renderings for outside insulation: a probabilistic approach based on the non-local continuum damage mechanics". He is an associated professor teaching Building Engineering, Building Physics and Project Engineering. Since 2001, he is also a professor at the Technical University of Eindhoven, The Netherlands. His research issues are: heat and mass transfer in heterogeneous, cracked, porous building materials; driving rain; durability physics and mechanics; X-ray computer tomography for moisture transfer identification and non-destructive testing of materials.

Professor Hugo Hens is founder and head of the Laboratory of Building Physics, Department of Civil Engineering, Katholieke Universiteit Leuven. He teaches Building Physics, Building Construction and Building Services. He earned his Ph.D. in 1975 at the same university with the dissertation "Theoretical and experimental study of the hygrothermal behaviour of building and insulating materials during interstitial condensation processes and drying, application on flat roofs.". He is member of several Building Physic related organisations and he wrote 114 papers and 5 books in the field of Building Physics. 